\title{
Artistic Conception of Blank Art in Chinese Painting
}

\author{
Wenxiu Li \\ School of Art and Design \\ Huanghe Science and Technology College \\ Zhenghzou, China
}

\begin{abstract}
Regardless of whether the ancient Chinese painting is the ink freehand brushwork or is the painting with fine brushworks and detail, it is not painted fully on the paper in the picture, and there are a lot of blank left. We generally call it the blank. In the traditional Chinese painting, the blank is not as the blank paper, it is an important constituent element, and is the part of forming a complete picture. "Blank" can be understood as an element of leaving proper space to give the main object enough space for stretching freely. Therefore, "blank" can't be understood as the "vanity". It is a kind of "hidden imagery" technique, and that's what the ancients said, "the more the scene hidden, the more profound the meaning." Blank has the irreplaceable significance and position in Chinese painting.
\end{abstract}

\section{Keywords-Chinese painting; blank; artistic conception}

\section{INTRODUCTION}

Nihility and reality complement is the artistic state of ancient Chinese art. Regarding the nihility and reality of the painting, there are many discourses in ancient Chinese painting. The nihility and reality began in the pre-Qin period, Laozi philosophy had the philosophical study on "great voice has no sound, great image has no form". The Wei Jin metaphysics in Northern and southern dynasties proposed the aesthetic theory of "the intangible world is being comes from not-being". In the Liu-Song period of Song Dynasty, Zong Bing wrote the earliest theory of landscape painting "Hua Shan Shui Xu", which embodied s the blood relationship between Chinese landscape painting and Taoist thought. The development to the tang dynasty, Liu Yuxi, Sikong Tu integrated Taoist aesthetics thinking and Buddhist aesthetics, and formed the complete artistic conception theory. Liu Yuxi proposed "artistic conception surpass the Image of the picture". He considered that all the artistic works which had profound artistic conception, except of having concrete physical real image, had intangible empty image associated with that, therefore, produced the artistic effect that there's an end to the words, but not to their message. Sikong Tu summarized it as "image out of images, scenery beyond scenery". And this empty image is like the voice in the air, the moon in the water, the flower in the mirror. It needs the viewers to use their own imagination to appreciate it, but is unspeakable. So, for the empty showed in the traditional Chinese painting, and the white embodied in the picture without bottom color added, what is the meaning of such aesthetics of leaving blank? This is a question worthy to be discussed

\section{THE CONCEPT AND FUNCTION OF BLANK}

Blank is a kind of important artistic techniques of Chinese painting. Just as its name implies, blank is leaving the corresponding blank in his works, gives the people the room for imagination. Leaving blank can get by appreciators aesthetic association and imagination to get a kind of image space. It is consistent with the Taoist thought in ancient China, and the traditional aesthetic consciousness, observation and memory way and artistic performance method, has distinctive national features. "The place without drawing becomes a wonderful aesthetic conception "is the peculiar aesthetic view point of the Chinese painting. Compared with other type of paintings, Chinese painting likes to leave large and small blank in the picture, and all kinds of blank. These blanks are not accidentally. Some has implied meaning of sky, and some has the implied meaning of water, and some has the implied meaning of clouds, and some may be nothing to express, it is a feeling, a kind of impression, or a kind of artistic conception. The blank in the Chinese painting is named "blank "."Blank art" with its most concise form to bear the most delicate emotions, has a "This silent wins audio" "understand tacitly" static aesthetic effect.

In the category of Chinese classical art, the traditional Chinese painting is not added the background. There are a lot of blank. The artists are pursuit of leaving blank of Chinese painting as a part of art higher aesthetic realm that is "the place without drawing becomes a wonderful aesthetic conception". The so-called "no ink place" is part of blank in the whole composition of the painting, not the vanity visually and insignificance, but enriches and improves its artistic expression of Chinese painting. Mr. Tian Xutong wrote in the book of "The Art of Blank": blank is the means of artistic expression. Using the blank technique can make the fictitious and realistic comparison of artwork, and unity of form and spirit. "The place without drawing becomes a wonderful aesthetic conception". The poets name the "blank" as the "connotation", and the calligraphers name it as "a style of calligraphy characterized by hollow strokes", and the painters name it "blank", and the musicians name it as " Very sound ". Blank, is one of the commonly used expression techniques of the artists in the creation

In this book "Picturesque Scene-Research on the Composition of Chinese Painting", Jiang Jin expounded the processing of blank and the artistic conception of blank and wrote: oil painting only talk about space, don't talk about blank, considers that blank does not exist in the nature. But traditional 
Chinese painting is precisely making an essay in this kind of "no image ", and that the blank is an important content of the "imagery". The blank in Chinese painting, also is the space of the "imagery". "Blank" cannot be understood as "nothingness ". It is a kind of "Hidden imagery" technique. "Hidden imagery "is like the "suspense" in the drama, and makes people to think more things by a little. This is what the ancients said, the more the scene hidden, the deeper the meaning. "Blank" is the plain white paper left in the Chinese painting, takes the invisible to be tangible. It is a very bold creation.

In the "Theory of Aesthetic Value Reckoning Blank as Inked in the Chinese Painting Creation", Chen Hongdong wrote that Chinese painting emphasizes on the actual reckoning blank as inked of the blank to make the empty reflecting the real. This "empty" is not only setting off the "real", but it is also the carrier of conveying the artistic conception. The particularity of the blank in the Chinese painting is wonderful in making the whole picture spirit; Chinese painters are mainly in the processing of empty environment, the place without drawing is a wonderful spot. Expressing the space by expansion, silent wins audio, the blank in the traditional Chinese painting is a kind of conception, needs to meet aesthetic of the people, if the whole picture is covered by the ink, it is no the art work but just a picture poster, so the traditional Chinese painting needs to have blank $\mathrm{n}$ the picture, to bring a kind of up-and-down rhythm sensation rhythm to the picture, so that further strengthen $\mathrm{s}$ the expressive force of the traditional Chinese painting works, constitutes a unique style of Chinese painting art. It makes the thinking of people longer and deeper, full of "hidden imagery" expression form. It expresses most beautiful and delicate affection in the simplest way, and is the important method to create the aesthetic interest of the Chinese painting that vacancy combines thousands of imagery.

\section{THE VALUE OF BLANK IN THE BUILDING OF ARTISTIC CONCEPTION OF CHINESE PAINTING}

In the field of Chinese classical aesthetics, the artistic conception is an important part of it, is the essence of Chinese painting aesthetics system. Chinese painting attaches great importance to the expression of artistic conception and the embodiment way, "blank" is a an important content of forming the formal beauty and artistic conception of the Chinese painting, and is related to the theme, artistic conception, interest of the of other various factors of the works and is one of keys to the success or failure of the painting. The layout of the "blank" in Chinese painting has its unique rigor, not something without foundation.

People take such blank which is able to produce such artistic conception and imagination as an important element of the Chinese painting. "Blank "means "nothingness ". This kind of painting language is an artistic conception of imagination.

"Nothingness" has the meaning of "inaction ", which plays the effect of "action through inaction ". The rhyme and wonderful leaving blank of Chinese ink painting on the vision with Laozi culture mental state, let "out of thin air" reached an intellectual level. No leaving blank picture is incomplete; no artistic conception of painting is without vitality. Chinese painting in the overall layout is in the pursuit of artistic conception, pays attention to set the scene. Usually it should start from the overall train of thought, and from the position, size and other aspects to take the comprehensive consideration of the blank, and pays attention to the unity of the formal beauty in picture composition. Blank is to extend the artistic conception of the picture. This is integrating with the thought of Laozi "two thing are deriving from one thing, three things are deriving from two things, the three begets all things of the world ".

The so-called leaving blank in the Chinese painting is not really empty blank, but reckons blank as inked, is a kind of the artistic state of taking empty as real. The blank in the fan painting in the song dynasty was almost accounting for more than half of the picture. Such as "Autumn Forest Water Bird", "Yanguan Temple", a corner of the water bank in the former picture was not drawn the water, and not showed the cliff. The painter just drew a corner of the mountain, neither drew the distant mountains and cloud and mist, but makes the viewer not feeling what is missing, but can produces the imagination far beyond image.

"Fishing alone at the Cold River" was drawn by Ma Yuan, with rigorous iron line drawing, and a tiny boat is drawn in the picture, and there is one old man who leaned on his ears on fishing and his body is slightly forward, beside the boat, the water lines are drawn by a few light ink pen. All around are almost blank. The painter drew very little, but the picture is not empty, on the contrary, the river water all around is broad, mist-covered waters with chill. In the blank, there is an interest and charm which is difficult to describe, shows a wide river and strong space, empty and shallow or is stagnant and Indifferent, makes people boundless imagination. The poetic interesting realm is the product combined with the mind and nature, and in art is the result of using the nihility and reality combination. This is "the actual "the combining of nihility and reality, and the place without drawing becomes a wonderful aesthetic conception".

The old gentleman Huang Binhong said that drawing was like playing chess, should be good at living eye. Painting must know the place of blank. Chinese painting is drawn the mountain, but not the drown the cloud, made the blank to be the boundless sea of clouds, and is drawn the shore but not drawn the water, made the blank to be a broad river and lake, is drawn the fishes but not drawn the water that the blank is the water of the fishes playing, and drawn the birds but not drawn the sky that the blank is the place where the birds fly... all are the pursuit of blank art. The trees and the stones in the modern Chinese landscape painting at the place light scattering are often leaving blank. The indoor and outdoor scenes of the figure painting can also use the actual contrast technique. Through the phase contrast of the real and empty scene, the association of the inside and outside of the painting, it creates the space feeling of the subjective consciousness. Dong Po said in his poem that: "Quiescence consequently can know the change of all things empty consequently can accept the realms of all things. "Using blank to express the ethereal hazy vivid artistic conception of all things", in the blank place, concentrating the effort of reckoning blank as inked", the 
nihility and reality combination expresses the unique ethereal beauty of Chinese painting, the wonderful beauty, to expand the artistic performance space.

Mr. Qi Baishi used the "blank" in his paining to express the artistic conception incisively and vividly. The works of Mr. Qi Baishi "Frog Voice out from Mountain Spring in Ten Miles", in the picture, there is no frog, but only a few lively little tadpoles which are swarming happily in turbulent flow. In the picture, it uses the frog tadpole shape which is the shape of the newborn frog to express artistic conception in poetry, this is an ingenious concept, makes the poetic achieving perfect convey --, under the set off of a distant mountains, a streak of riffle is effusing from the stone riprap of the mountain stream, and six small tadpoles are swaying in the rapid riffle to float downstream. They don't know has left the mother s of the frogs, also paddling and playing lively. From the immature tadpoles, people can image the mothers of the frogs outside the picture, due to loss of tadpoles, they would loudly tweet. Without frog voice is surpassing with frog voice. No a frog on is seen in the picture, it makes the person indistinctly hearing the frog voice in the distance and the galloping spring water, and playing a musical instrument, which has the effect of the combination with frog voice, and interprets the a poem by using the painting language. Mr. Qi Baishi used the painting to show the auditory organs feel things, rock deliberately use thick ink, and the place that spring to use the blank processing of large area, black and white and relative way of Chinese painting unique inked here used properly, the 'pre-pubescent the audible and depending on the specific phenomenon, through the lamp pen and ink. Let the viewer as if they are truly immersive, hear the front springs, and hear the sound of the little tadpole happy leap out of the water.

The space of the composition of a picture in the Chinese painting is expressed by a real and an empty flowing rhythm. This is expression unique of the space realm of Chinese painting. Chinese painting especially pays attention to artistic conception, and the particular way of the expression artistic conception can be "written" in the extra-image, and the viewers can get it from outside. The proof by facts that the management of the blank is the Infinite expansion and the greatest discovery of the Chinese painting to the aesthetic ideology, and Chinese painting creation is only to see the drawn place, but also has to see the place of blank. Only by the perfect combination of both, it can create excellent works of literature and art. Black is ink marks and also means reality; White is the blank of paper, also means nihility. Only knowing the blank can keep the black. The so-called blank is reckoning blank as inked. All painting master of Chinese painting is also the master-hand of controlling blank and using blank. In the blank place, it most can reflect the painting culture and artistic state of the painter. The blank in Chinese painting is the same important as the layout arrangement of black in the picture. Reckoning blank as inked is the unique art expression form of Chinese painting composition. Through visual symbols and conveying feeling and ideas, it is known as the artistic emotion language.

Chinese painting is through such rich philosophical artistic creation method of "blank", with a nihilistic, the form of blank conveys the rich artistic conception and connotation. The thickest part of the mountain reflects the deep part, and the static water reflects moving. Black is presented from white, and white is presented from black. Blank is not equal to nothing, but is the visible image beyond c invisible image, and the visible shape beyond the invisible shape, and the voice beyond the silence. Nihility and reality complement. "The place without drawing becomes a wonderful aesthetic conception. Using "blank" and "empty", it vividly performs the rich visual effect of relativity and intergeneration of the empty and reality, makes the realm of the" grasping truth" of people to the nature reflecting in the picture. The mutual effect in the heart, the ink marks cleverly presents the image and the blank and empty penetrates the spirit, even if the place where there is no ink marks, but there is lingering charm in the painting. This is the unique artistic conception creation of reckoning blank as inked of Chinese painting and the unique charm of Chinese painting formed from it.

\section{CONCLUSION}

It can be seen that leaving blank is the historical achievements in the development of Chinese painting art form. It enriches and develops the Chinese painting art expressive force, is a unique style of Chinese painting art. Chinese painting stresses artistic conception, and the artistic conception is appeared only in the way of mental state of the viewers. Leaving blank is just to give the mental state space of the viewers, and gives the works the extending breadth of the artistic conception. The ancients drew were leaving blank, and also was to show a relationship relation between heaven and man, o nihility and reality complement, existence and nothingness complement each other, which had a beauty of leisurely latency. But for the use of "blank", it is an art. At present, the leaving blank of the painting which is increasingly paying attention to the cultural spirit has become the unique visual language of Chinese traditional painting today. The effect of the "blank" for painting creation more cannot be ignored, which not only increases the artistic conceptions of painting, more gives the vast space of imagination works, has a positive meaning for the generation of excellent works.

\section{REFERENCES}

[1] Ma Liangshu: Chinese paintings morphology [M]. Beijing: Tsinghua university press, 2011.

[2] Jiang Jin: picturesque scene: research on composition of Chinese painting. Hunan fine arts publishing house, 1982

[3] Chen Hongdong: Theory of aesthetic value of reckoning blank as inked in the Chinese painting creation. Art guide, 2010 (5)

[4] Huang Zongxian: Outline of Chinese art history [M]. Chongqing: southwest normal university press, 1993

[5] Li Yuan: "Empty" and "real" in Chinese painting [J]. Master's thesis of Nanjing normal university, 2007

[6] Yu Meiqun: elementary analysis on The beauty of "leaving blank in Chinese painting " [N]. Journal of Qiongzhou university, 2008 (4) 